\title{
Modeling of Trace Elements and Heavy Metals Content in the Steppe Soils of Ukraine
}

\author{
Denys Breus ${ }^{1 *}$, Olha Yevtushenko ${ }^{1}$ \\ 1 Kherson State Agrarian and Economic University, Stritens'ka str. 23, 73006, Kherson, Ukraine \\ * Corresponding author's e-mail: breusd87@gmail.com
}

\begin{abstract}
The recent deterioration of the ecological condition of agricultural lands, the tendency of reducing soil fertility, and the production of plant products, mostly of low quality, necessitate an understanding of the role of trace elements in the process of plant formation. The content of trace elements in soils affects the efficiency of absorption of basic nutrients by plants. Deficiency of iron, manganese and zinc reduces the supply of nitrogen to plants. Copper and calcium promote the absorption of phosphorus by plants, but excess of iron inhibits it. Excess of copper and molybdenum reduces the transfer of potassium to plants. Due to high yields of agricultural crops, a significant amount of trace elements is removed from the soil, so the introduction of the optimal amount of trace elements against the background of high agricultural technology is an additional measure to increase the yields and quality of agricultural products. Heavy metals are an important environmental factor, which, on the one hand, is necessary for living organisms, and on the other (with increasing concentration of these elements in the environment) constitutes a negative factor in their lives. The activities of industrial enterprises, car exhausts and other attributes of civilization, increase the content of heavy metals in soils and as a consequence negatively affect their quality. The term "heavy metals" is used for the metals with a specific gravity exceeding $5 \mathrm{~g} / \mathrm{cm}^{3}$ or an atomic number of more than 20. Among them, lead and cadmium are considered the most dangerous. Therefore, modeling the content of trace elements and heavy metals in the Steppe soils of Ukraine is an additional mechanism for quality control of agricultural land and, as a consequence, of obtaining quality products to ensure food security of the state.
\end{abstract}

Keywords: trace elements, spatial modeling, heavy metals, agricultural lands, GIS-technologies.

\section{INTRODUCTION}

According to the analysis of the available scientific literature, the mobility of trace elements in the soil, their migration capacity, accumulation, removal and availability to agricultural plants are influenced by a number of factors (the content of macronutrients, calcium carbonates, soil moisture, etc.), including the organic matter content and the $p H$ of the soil solution. About $50 \%$ of the total amount of zinc and copper in the soil is strongly bound to organic matter and becomes available to crops only after mineralization. The copper in soils is present in a divalent form, it has a high migration capacity in an acidic environment, but under the conditions of high acidity, the trace element is fixed by organic matter. Under the conditions of the acidic $p H$ of the soil solution, the mobility of molybdenum (Mo) decreases, but the mobility of copper $(\mathrm{Cu})$, manganese $(\mathrm{Mn})$, zinc $(\mathrm{Zn})$, and cobalt (Co) increases. It is a known fact that the accumulation of $\mathrm{Zn}$ in crop yields occurs to a greater extent at soil pH 5.5 than at pH 6.2 (Dudiak et al., 2019).

A lot of modern scientists described the mobility of trace elements and concluded that the presence of particles rich in iron, manganese and hydrogen sulfide are the most important abiotic factors controlling the behavior of trace elements (Breus et al., 2020). That is, those metals that are sensitive to redox reactions $(\mathrm{Co}, \mathrm{Fe}, \mathrm{Mn})$, have a significant role in the processes of deposition and dissolution in the soils. The solubility of $\mathrm{Zn}$ in soils increases along with acidity. The factors that reduce the mobility of this element in soils are the presence of high levels of soluble 
phosphates, alkaline $\mathrm{pH}$ and lack of moisture. The plants grown on sod-podzolic loam soils accumulated more zinc than on chernozem soils. Steppe soils were defined as characterized by low supply of agricultural plants with mobile compounds of trace elements (Breus et al., 2021).

The soil solutions from humus horizons contain organic components capable of forming complexes with metal ions, which affect their mobility and, accordingly, availability to plants. Organic matter reduces to the greatest extent the absorption by plants of calcium, iron, copper, cobalt and molybdenum, and to a lesser extent magnesium, manganese, boron, phosphorus, potassium and zinc. In other words - the increase of organic matter content in soils decreases the concentration of elements in plants (Dudiak et al., 2020).

In the scientific literature there are contradictory conclusions about the absorption of trace elements by plants from the soil. According to authors (Lisetskii et al. 2016), there is a direct positive relationship between the number of elements in soils and their concentration in plants. Other researchers (Anasri et al., 2016), on the contrary, deny the existence of a positive correlation between the content of elements in soils and plants.

This happens due to the fact that the amount of nutrients extracted from homogeneous soils will have a greater or lesser correlation with the concentration of these elements in plants. Increasing the concentration of the element in the soil has a positive effect both on its amount, which is passed to the extractant, and the content of this element in plants. A completely different result is obtained when comparing the data on the content of elements in soils and plants with a wider range of soils characterized by different properties. In this case, the influence of soil factors overlaps the positive dependency between the content of the element in the soil and its absorption by plants (Skrylnyk et al., 2018).

Manganese (Mn) is involved in the process of photosynthesis and synthesis of vitamin $\mathrm{C}$, the content of which is an indicator of fruit quality. The Mn deficiency is most often observed in the soils with a neutral or alkaline $\mathrm{pH}$, especially on sandy and loamy soils (Lisetskii et al., 2020a)

Copper $(\mathrm{Cu})$ promotes normal growth and development of the plant. With insufficient supply of $\mathrm{Cu}$ plants stop growing due to violation of the insemination process of cereals and fruit trees. The optimal level of $\mathrm{Cu}$ is $3-8 \mathrm{mg} / \mathrm{kg}$ of available element in the soil. Copper is strongly adsorbed in carbonate soils with a high $\mathrm{pH}$ level. Low $\mathrm{pH}$ also limits the availability of the element. The availability of $\mathrm{Cu}$ for plants is directly related to the $\mathrm{Zn}$ content in the soil. Copper is absorbed in the same form as zinc, so an excess of one of these elements in the soil makes unavailable for plants the other element (Lisetskii et al., 2020b).

Cobalt (Co). An important characteristic of the quality of agricultural land is its cobalt content. Consumption of cobalt by plants occurs in the form of $\mathrm{Co}^{2+}$ ions or chelates in small quantities. Cobalt is a necessary trace element for the binding of atmospheric nitrogen.

Zinc ( $\mathrm{Zn})$. The content of zinc in the Earth's crust is $50 \mathrm{mg} / \mathrm{kg}$. $\mathrm{Zn}$ is known to be mobile and bioavailable in light acidic and mineral soils. Maximum permissible concentrations (MPC) of gross forms of $\mathrm{Zn}$ are in soil $100 \mathrm{mg} / \mathrm{kg}$ and, mobile forms $23 \mathrm{mg} / \mathrm{kg}$. Zinc is a trace element, which in small quantities is necessary to ensure many physiological and biochemical processes and reactions, but at high concentrations in the environment causes a number of negative processes. By forming complexes with organic ligands, $\mathrm{Zn}$ at the intracellular level can acquire form which is unavailable for plants.

Among heavy metals, cadmium and lead, which are characterized by significant stability, high toxicity and cumulative properties, are the objects of constant agroecological monitoring. Particularly dangerous are the mobile forms of $\mathrm{Cd}^{2+}$ and $\mathrm{Pb}^{2+}$ in the soil, which determine the level of danger to plants, and ultimately to humans (Pichura et al., 2021a)

Therefore, today the scientific community is faced with the urgent issue of developing, studying and implementing an effective monitoring system of soils under specific soil and climatic conditions, to determine the presence of trace elements and heavy metals, restoring its fertility, as well as increasing protective and buffering properties of soil systems for obtaining environmentally friendly products.

The objective of the study was to determine the spatial heterogeneity of trace elements and heavy metals distribution in the Steppe zone soils of the South of Ukraine using the cartographic method, statistical models and GIS-technologies.

\section{MATERIAL AND METHODS}

In order to implement the objective of the article, the spatio-temporal method of assessing 
the changes in the content of trace elements and heavy metals in the Steppe zone soils was used. The studies were conducted in the certified laboratories of the Kherson branch of the "Institute of Soil Protection of Ukraine" State Institution. The samples were taken on 296 stationary posts of soil agro-ecological monitoring in the layer $0-20 \mathrm{~cm}$ during the 9-th round of agrochemical certification of lands (Boiko et al, 2018).

The study was carried out by using the cartographic method, which allows visualizing information and research results, by establishing the spatio-temporal links and forecasting the spatial heterogeneity of the distribution of trace elements in the researched agricultural lands. Modeling was carried out using the ArcGIS 10.1 and Statistica software packages. This provided a qualitative interpretation of spatial and graphical information and modeling results (Pichura et al., 2021b)

\section{RESULTS AND DISCUSSION}

The content of mobile forms of manganese in the Steppe soils of the Kherson region (Ukraine) is in the range of 3.02-32.01 mg/kg (Fig. 1a). The distribution of Mn depends on the redox processes in the soil, air and temperature regimes, and the reaction of the soil solution. The Mn content in soils, which corresponds to qualitative gradations from medium to high content ( $>10.0 \mathrm{mg} / \mathrm{kg}$ ), characterizes $77.5 \%$ of the researched area of agricultural land (Table 1). The soils with a high level of Mn content are located in the Nizhniy Sirogozsky and Gornostaevsky districts of the Kherson region, whereas those with low level in the Belozersky and Berislavsky districts.

a)

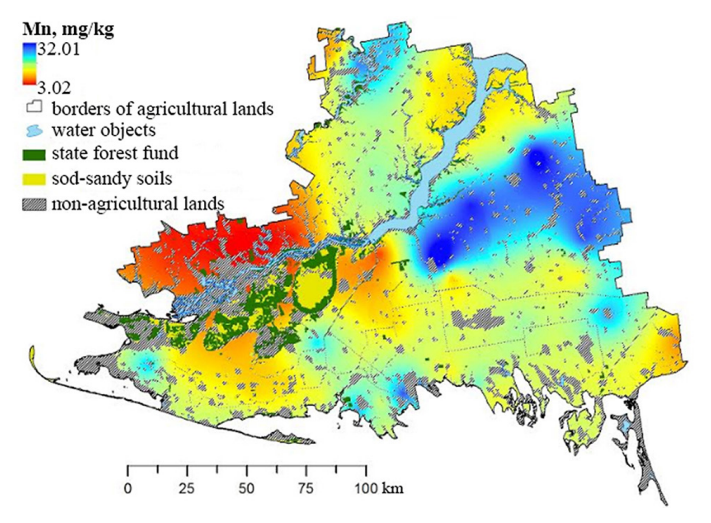

The content of mobile forms of copper in the soil of the region varies between $0.07-1.61 \mathrm{mg} / \mathrm{kg}$ (Fig. 1b). The $\mathrm{Cu}$ content in soils, which corresponds to qualitative gradations from medium to high content $(>0.20 \mathrm{mg} / \mathrm{kg}$ ) characterizes $95.4 \%$ of the investigated area of agricultural land (Table 1). The highest content of $\mathrm{Cu}(>0.50 \mathrm{mg} / \mathrm{kg})$ detected in the soils of the region corresponds to the agricultural lands of the Oleshky district, the lowest $(<0.20 \mathrm{mg} / \mathrm{kg})$ to the lands of the Blozersky and Beryslavsky districts.

The content of mobile zinc ( $\mathrm{Zn}$ ) compounds in the soils of Ukraine is $0.2-2 \mathrm{mg} / \mathrm{kg}$ of soil. About $60 \%$ of arable soils in Ukraine have a low content of $\mathrm{Zn}$ - an average of $0.2 \mathrm{mg} / \mathrm{kg}$ of soil. The main causes of zinc deficiency are low natural concentration of zinc available to plants in soils, which are associated with low gross element content in soils. The factors that cause low zinc mobility in soils are high content of iron hydroxides, carbonates, organic compounds, and phosphates. The content of mobile forms of $\mathrm{Zn}$ in the soils of the region was determined at a low level (0.35-1.49 mg/kg) (Fig. 2a). The highest content of zinc $(>1.0 \mathrm{mg} / \mathrm{kg})$ was determined in the soils of the Kalanchak and Skadovsk districts, wheteas the lowest $(<0.50 \mathrm{mg} / \mathrm{kg})-$ in the soils of the Gornostaivsky and Beryslavsky districts.

The content of mobile forms of cobalt (Co) in the soils of the region is in the range of $0.06-0.81 \mathrm{mg} / \mathrm{kg}$ (Fig. 2b). The Co content in soils, which corresponds to qualitative gradations from medium to high content $(>0.15 \mathrm{mg} / \mathrm{kg}$ ) characterizes $98.7 \%$ of the area of agricultural land (Table 2). The highest content of cobalt $(>0.6 \mathrm{mg} / \mathrm{kg})$ was detected in the soils of the Nizhniy Sirogozhsky and Genichesky districts,

b)

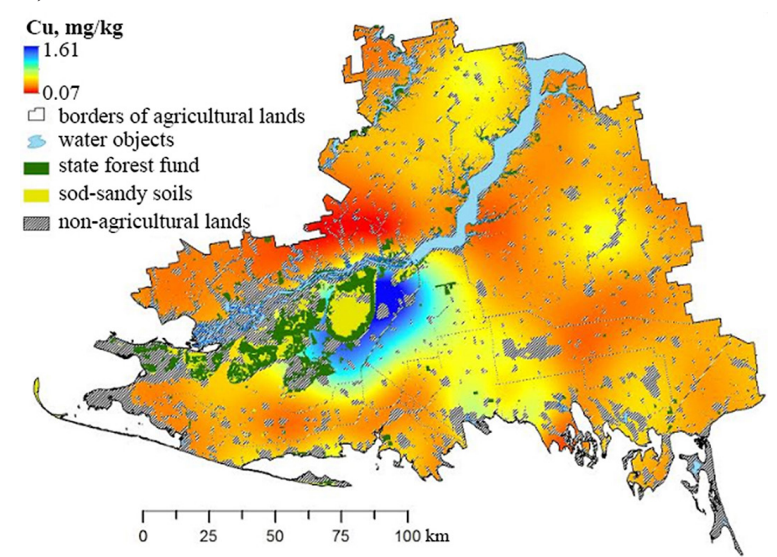

Figure 1. Cartogram of the spatial distribution of mobile forms of trace elements in the soils of the Kherson region (Ukraine): $a$ - manganese; $b$-copper 
a)

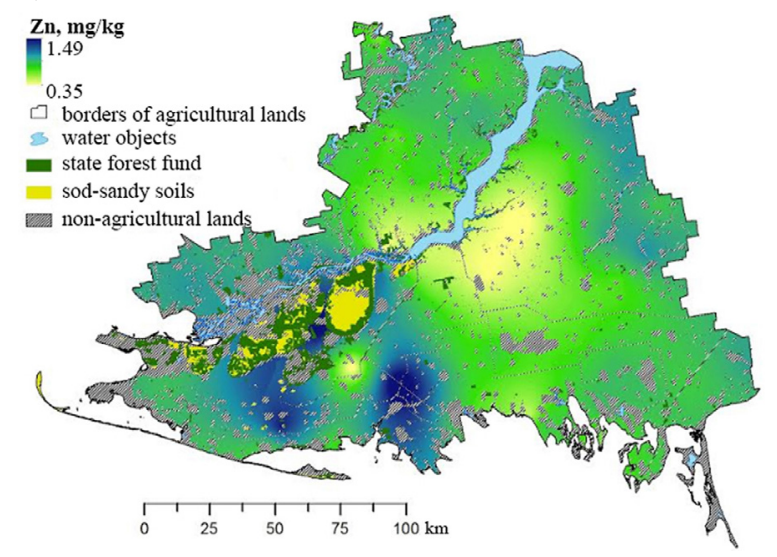

b)

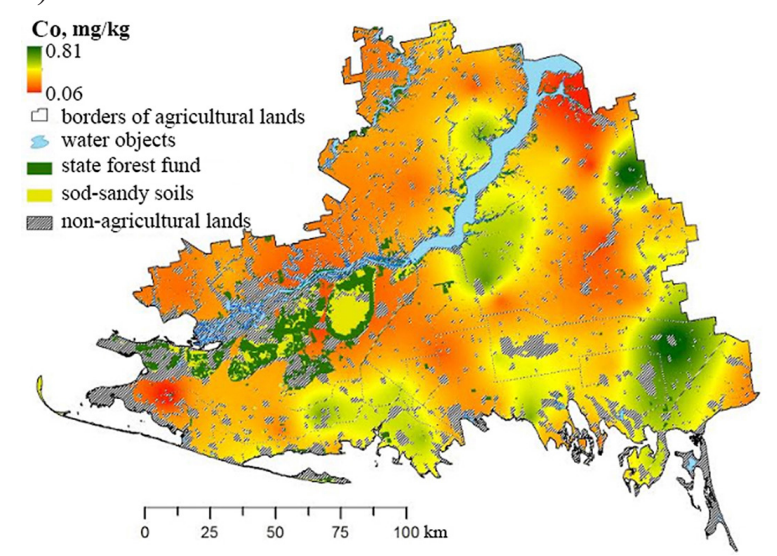

Figure 2. Cartogram of the spatial distribution of mobile forms of trace elements in the soils of the Kherson region (Ukraine): $a$-zinc; $b$ - cobalt

while the lowest $(<0.15 \mathrm{mg} / \mathrm{kg}) \quad$ - in the soils of the Verkhnorogachytsky and Holoprystansky districts.

The functions of the spatial distribution of mobile forms of trace elements in the soils of the Kherson region are presented in Table 2.

According to the 9-th round of agrochemical survey of agricultural lands of the region conducted by the Kherson branch of the "Institute

Table 1. Distribution of mobile forms of trace elements in soils of agricultural lands of the Kherson region

\begin{tabular}{|c|c|c|c|}
\hline \multicolumn{2}{|c|}{ Trace elements, mg/kg } & \multicolumn{2}{|l|}{ Area } \\
\hline Gradation & Content & Thousand hectares & $\%$ \\
\hline \multicolumn{4}{|c|}{ Manganese $(M n)$} \\
\hline Low & $<10.0$ & 398.2 & 22.4 \\
\hline Medium & $11.0-20.0$ & 1146.6 & 64.5 \\
\hline High & $>20.0$ & 231.1 & 13.0 \\
\hline \multicolumn{4}{|c|}{ Copper $(\mathrm{Cu})$} \\
\hline Low & $<0.20$ & 81.8 & 4.6 \\
\hline Medium & $0.21-0.50$ & 1303.0 & 73.3 \\
\hline High & $>0.50$ & 392.8 & 22.1 \\
\hline \multicolumn{4}{|c|}{$\operatorname{Zinc}(Z n)$} \\
\hline \multirow{7}{*}{ Low } & $<0.4$ & 33.8 & 1.9 \\
\hline & $0.41-0.60$ & 222.2 & 12.5 \\
\hline & $0.61-0.80$ & 501.3 & 28.2 \\
\hline & $0.81-1.00$ & 723.5 & 40.7 \\
\hline & $1.01-1.20$ & 165.3 & 9.3 \\
\hline & $1.21-1.40$ & 87.1 & 4.9 \\
\hline & $1.41-150$ & 44.4 & 2.5 \\
\hline \multicolumn{4}{|c|}{ Cobalt (Co) } \\
\hline Low & $<0.15$ & 23.1 & 1.3 \\
\hline Medium & $0.16-0.30$ & 878.1 & 49.4 \\
\hline High & $>0.30$ & 876.4 & 49.3 \\
\hline \multicolumn{2}{|c|}{ Total } & 1777.6 & 100 \\
\hline
\end{tabular}

of Soil Protection of Ukraine" State Institution, 16080 samples were selected and analyzed for the copper and zinc content, as well as 20340 samples for the lead and cadmium content. The samples were found to contain a slight excess of the maximum permissible concentration (MPC) of heavy metal salts, in particular - one sample with an excess of copper content $-3.45 \mathrm{mg} / \mathrm{kg}$ (MPC $-3.0 \mathrm{mg} / \mathrm{kg}$ ). The area of pollution within the Solontsi village in the Oleshkivsky district amounted to 56 hectares. Excess of zinc content was determined in the Fedorivka village in the Novotroitsky district $(\mathrm{Zn}-24.3 \mathrm{mg} / \mathrm{kg}$; MPC $23.0 \mathrm{mg} / \mathrm{kg}$ ), the area of pollution amounted to 342 hectares.

Graphical and statistical characteristics of the spatial heterogeneity of the distribution of cadmium content are presented in Figure 3. As a result of the autocorrelation analyses of the spatial heterogeneity of cadmium distribution, the minimum $(r=0.103)$ and maximum $(r=0.013)$ radii of typical cadmium formation were determined, which were from $2.5 \mathrm{~km}$ up to $5.0 \mathrm{~km}$. The content of cadmium (Cd) in the soils of the region according to the 9-th round is in the range of $0.02-0.42 \mathrm{mg} / \mathrm{kg}$. The Cd content, which corresponds to a value of $0.20<\mathrm{Cd}<0.40 \mathrm{mg} / \mathrm{kg}$, characterizes $48.8 \%$ of the area of agricultural land (Table 3).

$$
\begin{aligned}
& f(C d)=-2,008 \cdot x-5,318 \cdot y-0,011 \cdot x^{2} \\
& +0,061 \cdot x \cdot y+0,034 \cdot y^{2}+158,56 ; R=0,57
\end{aligned}
$$

where: $x$ - longitude, decimal degrees, $y$ - latitude, decimal degrees 
Table 2. Functions of content and spatial distribution of mobile forms of microelements in the soils of the Kherson region

\begin{tabular}{|c|c|c|}
\hline $\begin{array}{c}\text { Trace } \\
\text { elements }\end{array}$ & Functions & $\mathrm{r}$ \\
\hline \multicolumn{3}{|c|}{ Function of content } \\
\hline $\mathrm{Mn}$ & $f(M n)=156,4 \cdot \sin (0,02119 x+1,678)+129,4 \cdot \sin (0,0247 x+4,67)+0,141 \cdot \sin (0,1852 x-1,691)$ & 0.99 \\
\hline $\mathrm{Cu}$ & $f(C u)=7,21 \cdot \sin (0,02184 x+1,882)+6,403 \cdot \sin (0,04527 x+3,798)+2,31 \cdot \sin (0,07234 x+5,5)+0,3048 \cdot \sin (0,1102 x+6,619)$ & 0.99 \\
\hline $\mathrm{Zn}$ & $f(Z n)=14,09 \cdot \sin (0,005309 x+2,798)+3,549 \cdot \sin (0,02138 x+5,123)+0,07894 \cdot \sin (0,07862 x+4,951)$ & 0.99 \\
\hline Co & $f(C o)=5,299 \cdot \sin (0,009494 x+2,542)+2,69 \cdot \sin (0,01862 x+5,218)+0,03163 \cdot \sin (0,08123 x+5,265)$ & 0.98 \\
\hline \multicolumn{3}{|c|}{ Function of spatial distribution } \\
\hline $\mathrm{Mn}$ & $f(M n)=-263,50 \cdot x-107,26 \cdot y-1,76 \cdot x^{2}+8,28 \cdot x \cdot y-1,82 \cdot y^{2}+6849,82$ & 0.67 \\
\hline $\mathrm{Cu}$ & $f(C u)=5,57 \cdot x+11,32 \cdot y-0,13 \cdot x^{2}+0,07 \cdot x \cdot y-0,15 \cdot y^{2}-353,44$ & 0.39 \\
\hline $\mathrm{Zn}$ & $f(Z n)=-16,68 \cdot x-45,41 \cdot y+0,11 \cdot x^{2}+0,20 \cdot x \cdot y-0,41 \cdot y^{2}+1345,44$ & 0.52 \\
\hline Co & $f(C o)=0,15 \cdot x-4,68 \cdot y-0,003 \cdot x^{2}+0,003 \cdot x \cdot y+0,048 \cdot y^{2}+108,02$ & 0.52 \\
\hline
\end{tabular}

Table 3. Distribution of the cadmium content in the soils of agricultural lands of the region

\begin{tabular}{|c|c|c|}
\hline \multirow{2}{*}{ Cadmium, mg/kg } & \multicolumn{2}{|c|}{ Area } \\
\cline { 2 - 3 } & $\begin{array}{c}\text { Thousand } \\
\text { hectares }\end{array}$ & $\%$ \\
\hline$<0.10$ & 138.7 & 7.8 \\
\hline $0.11-0.20$ & 771.5 & 43.4 \\
\hline $0.21-0.30$ & 730.6 & 41.1 \\
\hline $0.31-0.40$ & 136.9 & 7.7 \\
\hline Total & 1777.6 & 100 \\
\hline
\end{tabular}

a)

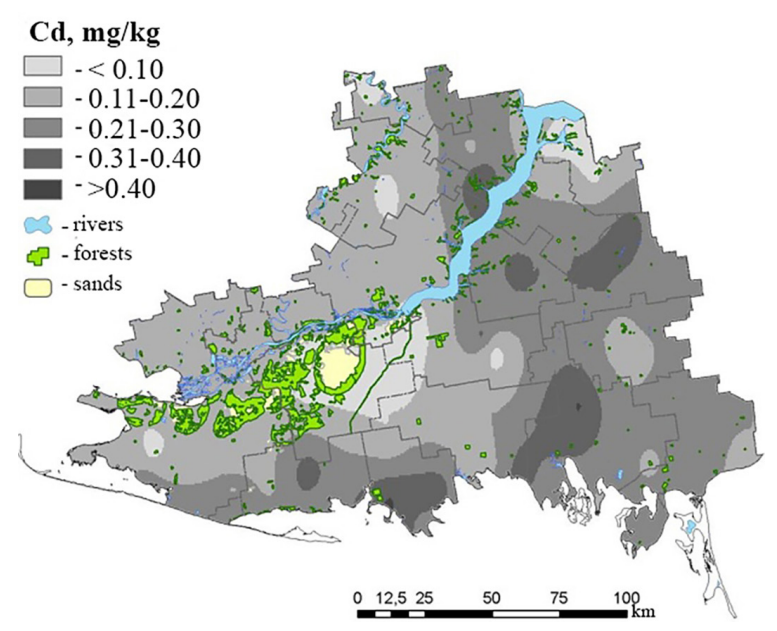

$f(C d)=3,586 \cdot \sin (0,01261 x+2,418)+2,397$ $\sin (0,0275 x+4,839)+0,5174 \cdot \sin (0,04556 x+7,071)$

$$
r=0,998
$$

During the research period, the value of lead content in the soils of the Kherson region did not exceed the value of the maximum permissible concentration $-6.0 \mathrm{mg} / \mathrm{kg}$ of soil. Graphical and statistical characteristics of the spatial

b)

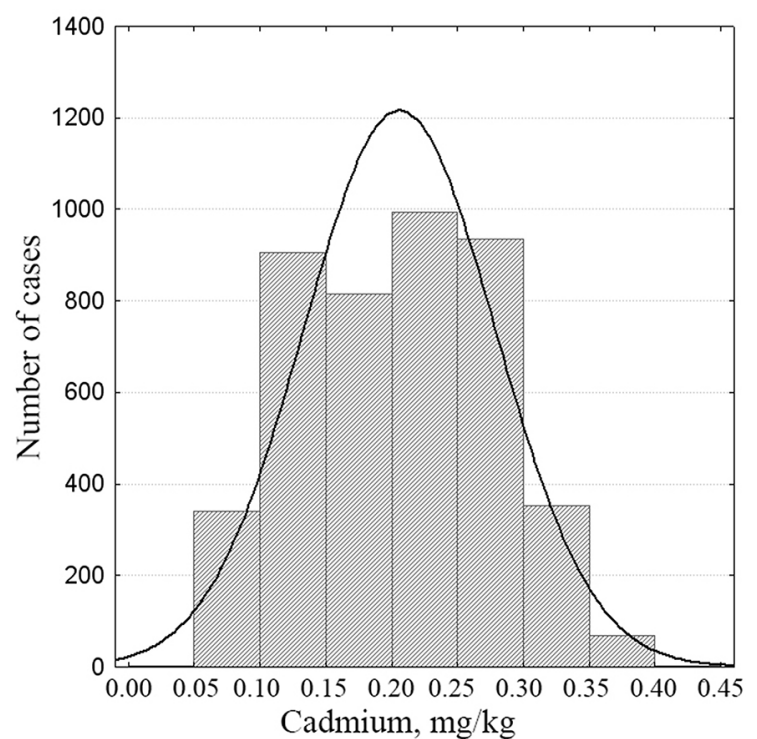

Figure 3. Statistical-cartographic characteristics of cadmium distribution in the layer of $0-20 \mathrm{~cm}$ in the soils of the region: $a$-cartogram of distribution; $b$ - the function of spatial distribution; $c$ - the function of providing soils with humus; $d$-statistical characteristics 
heterogeneity of the lead content distribution are presented in Figure 4. As a result of the autocorrelation analyses of the spatial heterogeneity of lead content distribution, the minimum $(r=0.065)$ and maximum $(r=0.030)$ radii of typical lead formation conditions were determined, which are from $2.5 \mathrm{~km}$ to $10.0 \mathrm{~km}$.

$$
\begin{aligned}
& f(P b)=18,225 \cdot x-0,013 \cdot y-0,053 \cdot x^{2}- \\
& -0,313 \cdot x \cdot y+0,106 \cdot y^{2}-296,305 ; R=0,55
\end{aligned}
$$

where: $x$-longitude, decimal degrees, $y$ - latitude, decimal degrees

$$
\begin{gathered}
f(P b)=28,13 \cdot \sin (0,02061 x+1,965)+28,87 . \\
\cdot \sin (0,03053 x+4,623)+7,213 \cdot \sin (0,0434 x+7,116) \\
r=0,990
\end{gathered}
$$

Table 4. Distribution of the lead content in the soils of agricultural lands of the region

\begin{tabular}{|c|c|c|}
\hline \multirow{2}{*}{ Lead, mg/kg } & \multicolumn{2}{|c|}{ Area } \\
\cline { 2 - 3 } & $\begin{array}{c}\text { Thousand } \\
\text { hectares }\end{array}$ & $\%$ \\
\hline$<0.50$ & 62.2 & 3.5 \\
\hline $0.51-1.00$ & 387.5 & 21.8 \\
\hline $1.01-1.50$ & 885.2 & 49.8 \\
\hline $1.51-2.00$ & 336.0 & 18.9 \\
\hline $2.01-2.50$ & 83.5 & 4.7 \\
\hline $2.51-3.00$ & 17.8 & 1.0 \\
\hline$>3.00$ & 5.3 & 0.3 \\
\hline Total & 1777.6 & 100 \\
\hline
\end{tabular}

a)

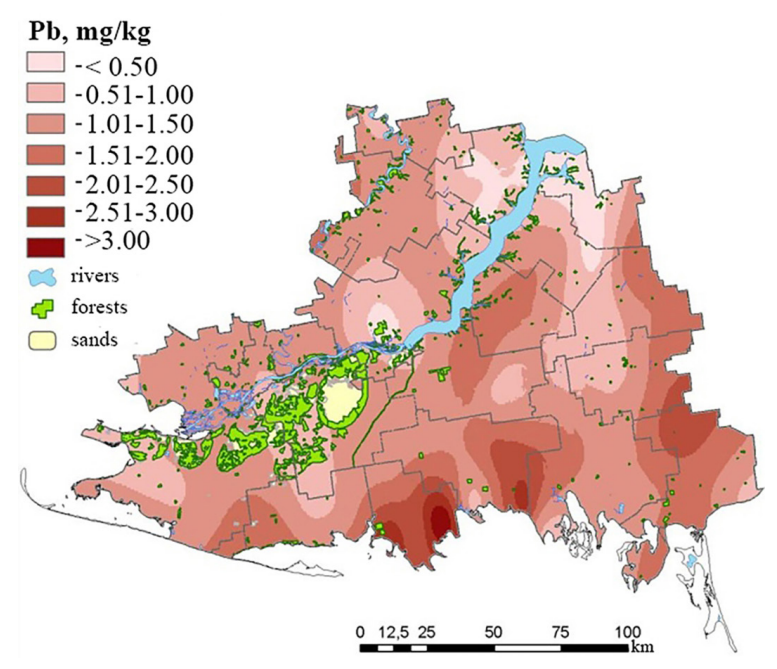

The content of lead in the soils of the region is in the range of $0.19-3.43 \mathrm{mg} / \mathrm{kg} ; 80 \%$ of the area of agricultural land contains $0.71-1.83 \mathrm{mg} / \mathrm{kg}$ of lead (Table 4).

\section{CONCLUSIONS}

The regularities of mobile forms of trace elements distribution in the soil were identified, in particular, manganese is in the range of $3.1 \mathrm{mg} / \mathrm{kg}$ (low) to $32.1 \mathrm{mg} / \mathrm{kg}$ (high), copper $0.03 \mathrm{mg} / \mathrm{kg}$ (low) to $1.6 \mathrm{mg} / \mathrm{kg}$ (high), zinc in the soils of the region was determined at a low level - $0.3-1.5 \mathrm{mg} / \mathrm{kg}$, cobalt $-0.06 \mathrm{mg} / \mathrm{kg}$ (low) to $0.81 \mathrm{mg} / \mathrm{kg}$ (high).

In the 9-th round of the survey, 15 samples of soil were detected to contain an excess of $\mathrm{Pb}$ content $-8.32 \mathrm{mg} / \mathrm{kg}$ (MPC $-6.0 \mathrm{mg} / \mathrm{kg}$ ) on a total area of 425 ha in the Sivash village in the Novotroitsky district and in the Ivanivka village in the Vysokopilsky district. Moreover, 24 soil samples were found to exhibit excess $C d$ content $-0.97 \mathrm{mg} / \mathrm{kg}$ (MPC $-0.7 \mathrm{mg} / \mathrm{kg})$ in the Henichesk and Novotroitsk districts with a total area of pollution of 459 ha. The cause of soil contamination of agricultural lands was the unregulated use of agrochemicals.

Therefore, the use of modern methods of monitoring the agro-ecological condition of soils with the use of modeling, mapping and GIS-technologies in the context of intensive use

b)

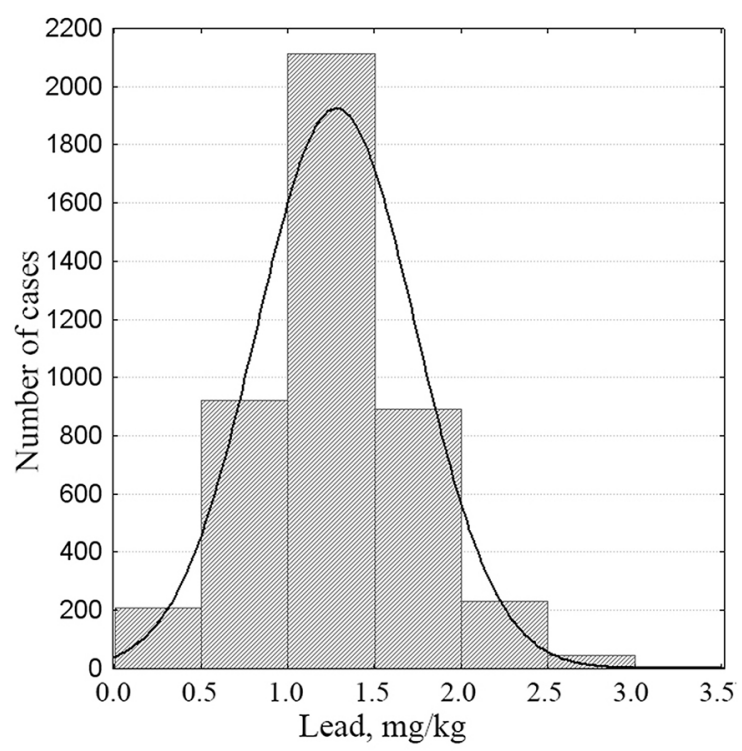

Figure 4. Statistical-cartographic characteristics of the lead distribution in the layer of $0-20 \mathrm{~cm}$ in soils of the region: $a$ - cartogram of distribution; $b$ - the function of spatial distribution; $c$ - the function of providing soils with humus; $d$-statistical characteristics 
of land resources is an integral part of modern methods of environmental protection and food security of the countries.

\section{REFERENCES}

1. Anasri B.P., Ramesh H. 2016. Assessment of soil erosion by RUSLE model using remotrsensing and GIS-A case study of Nethravathi Basin. Geoscience Frontiers, 7(6), 953-961.

2. Boiko T.O., Boiko P.M., Breus D.S. 2018. Optimization of shelterbelts in the Steppe zone of Ukraine in the context of sustainable development. Proc. 18-th International Multidisciplinary Scientific GeoConference SGEM 2018, 871-876.

3. Breus D., Yevtushenko O., Skok S., Rutta O. 2020. Method of forecasting the agro-ecological state of soils on the example of the South of Ukraine. Proc. 20-th International Multidisciplinary Scientific GeoConference SGEM 2020, 523-528.

4. Breus D.S., Skok S.V. 2021. Spatial modelling of agro-ecological condition of soils in Steppe zone of Ukraine. Indian Journal of Ecology, 48(3), 627-633.

5. Breus D., Dudyaeva O., Evtushenko O., Skok S. 2018. Organic agriculture as a component of the sustanable development of the Kheson region (Ukraine). Proc. 18-th International Multidisciplinary Scientific GeoConference SGEM 2018, 691-697.

6. Dudiak N.V., Pichura V.I., Potravka L.A., Stroganov A.A. 2020. Spatial modeling of the effects of deflation destruction of the steppe soils of ukraine. Journal of Ecological Engineering, 21(2), 166-177. DOI: $10.12911 / 22998993 / 116321$
7. Dudiak N.V., Potravka, L.A., Stroganov A.A. 2019. Soil and climatic bonitation of agricultural lands of the steppe zone of ukraine. Indian Journal of Ecology, 46(3), 534-540.

8. Lisetskii F.N., Poletaev A., Zelenskaya E., Pichura V. 2020a. Associated data on the physicochemical properties of pedosediments, climatic and dendrochronological indicators for palaeogeographic reconstructions. Data in Brief, 28. DOI: 10.1016/j. dib.2019.104829

9. Lisetskii F.N., Pichura V.I. 2016. Assessment and forecast of soil formation under irrigation in the Steppe zone of Ukraine. Russian Agricultural Sciences, 42(2), 154-158.

10. Lisetskii F.N., Pichura V.I. 2020b. Catena linking of landscape-geochemical processes and reconstruction of pedosedimentogenesis: A case study of defensive constructions of the mid-17th century, south Russia. Catena, 187. DOI: 10.1016/j. catena.2019.104300

11. Pichura V., Potravka L., Dudiak N., Stroganov A., Dyudyaeva O. 2021a. Spatial differentiation of regulatory monetary valuation of agricultural land in conditions of widespread irrigation of steppe soils. Journal of Water and Land Development, 48(1-3), 182-196. DOI: 10.24425/jwld.2021.136161

12. Pichura V., Potravka L., Dudiak N., Vdovenko N. 2021b. Space-time modeling of climate change and bioclimatic potential of steppe soils. Indian Journal of Ecology, 48(3), 671-680.

13. Skrylnyk Ye., Kutova A., Hetmanenko V. 2018. The value of soil fertility indicators of optimizing microelement nutrition of plants. Ecologic sciences, 20(2), 65-68. 